\title{
Relation of genotype 22q11 deletion to phenotype of pulmonary vessels in tetralogy of Fallot and pulmonary atresia-ventricular septal defect
}

\author{
M Chessa, G Butera, P Bonhoeffer, L Iserin, J Kachaner, S Lyonnet, A Munnich, D Sidi, \\ D Bonnet
}

Service de Cardiologie Pédiatrique, Hôpital Necker/Enfants

Malades, 149 rue de Sèvres, 75015 Paris, France

M Chessa

G Butera

P Bonhoeffer

L Iserin

J Kachaner

D Sidi

D Bonnet

Unité de Recherches sur les Handicaps Génétiques de l'Enfant, INSERM

U393, Hôpital

Necker/Enfants

Malades

S Lyonnet

A Munnich

Correspondence to: Dr Bonnet.

Accepted for publication 3 October 1997

\begin{abstract}
Objective-To compare the morphology of the pulmonary vessels in tetralogy of Fallot or pulmonary atresia-ventricular septal defect (PA-VSD) with (de122q) and without 22q11 deletion (non-del22q).

Patients-94 consecutive infants (54 with tetralogy of Fallot, 40 with PA-VSD) were studied using ultrasound and catheterisation.

Molecular investigations-Identification of the 22q deletion was performed either by fluorescent in situ hybridisation or polymerisation chain reaction genotyping.

Results-25 patients were de122q (16/40 (40\%) PA-VSD $v$ 9/54 (17\%) tetralogy of Fallot; $p<0.02)$. Major aortopulmonary collateral arteries was more common in patients with PA-VSD-del22q $(p<0.03)$. Such collaterals were identified in 13 patients: 10 del22q and three non-del22q $(p<0.001)$. The size of the right and left pulmonary arteries expressed as a standard deviation (SD) difference of the normal range was -4.2 (quartiles -5.3 and -2.9) for PA-VSD del22q, and $-2.6(-3.1$ and -1.8) for PA-VSD non-del22q $(p=0.02)$. The mean (SD) difference between the measured and theoretical Nakata index was -373 (94) for PA-VSD del22q $v-245$ (93) in PA-VSD non-del22q $(p=0.0002)$. In tetralogy of Fallot patients with and without del22q, the size of the pulmonary arteries was similar $(p=0.6)$. Conclusions-A "specific" phenotype could be defined in patients with deletion: PA-VSD, major aortopulmonary collateral arteries with complex loop morphology, and small central pulmonary arteries. Differences in the morphology of the pulmonary vessels may indicate a different timing of the faulty developmental pathway in patients with and without 22q11 deletion.

(Heart 1998;79:186-190)
\end{abstract}

Keywords: 22q deletion; tetralogy of Fallot; congenital heart disease

Conotruncal cardiac malformations account for approximately $50 \%$ of congenital heart defects in newborn infants. Recently, hemizygosity for 22q11.2 has been reported in patients with the DiGeorge syndrome and related disorders, including the velo-cardio- facial syndrome, the conotruncal anomaly face syndrome, and the Cayler cardiofacial syndrome. ${ }^{1-4}$ These disorders most frequently occur de novo and cause impaired development of the cardiac outflow tract, resulting in conotruncal malformations. ${ }^{5}$ As has been shown by Kirby and Le Douarin and their colleagues, depleting the heart of cells derived from occipital neural crest may result in aortopulmonary septal defects. ${ }^{67}$ The exact role of the neural crest cells that migrate into the tunica media of the visceral arch arteries during conotruncal formation remains obscure. ${ }^{7}$ However, it appears that there is an important gene connected with the truncus arteriosus and pulmonary artery development in the $22 \mathrm{q} 11$ region. The cardiac defects most commonly encountered in patients with $22 \mathrm{q} 11$ deletion in previously reported series are type B interrupted aortic arch (30-45\%), truncus arteriosus (14-25\%), and tetralogy of Fallot or pulmonary atresia-ventricular septal defect (PA-VSD) in $20 \% .{ }^{58}$ Some phenotypic differences have been shown between patients with and without the $22 \mathrm{q} 11$ deletion. ${ }^{9}{ }^{10}$ Hitherto, however, specific differences of the pulmonary vessels in tetralogy of Fallot or PA-VSD in these patients remain unknown. Genotypephenotype correlations in these types of congenital heart disease may help our understanding of pulmonary vasculature maldevelopment and provide a key to the genetic heterogeneity of conotruncal heart defects.

The purpose of our study was to compare the morphology of the pulmonary arteries and the origin, course, and connections of the major aortopulmonary collateral arteries in patients with tetralogy of Fallot and PA-VSD, with or without chromosome 22q11 deletion.

\section{Methods}

From January 1992 to September 1996, 94 infants were enrolled prospectively into the study. They were all referred to our institution for tetralogy of Fallot or PA-VSD before the age of six months. Each affected individual was examined by a clinical geneticist who was not informed of the laboratory results before the examination.

CARDIOVASCULAR ANOMALIES

All patients underwent catheterisation and angiography. Ultrasound evaluation was performed on an Acuson XP 128 system using 5 to $7.5 \mathrm{MHz}$ transducers. The relevant morphological features were: anomalies of the aortic 
arch, anomalies of the arterial duct, size and confluence of central pulmonary arteries, and morphology of major aortopulmonary collateral arteries when present. Major aortopulmonary collateral arteries were defined as arteries originating from the aorta or its branches and connecting to the peripheral pulmonary arteries or supplying the pulmonary blood flow for a segment or a lobe of the lung without connection to the central pulmonary arteries. Such collaterals were classified as type I-bronchial artery branch, type II-direct aortic branch, type III-indirect aortic branch. ${ }^{11}$ The size of the pulmonary arteries was measured by using angiographic data for each patient. The pulmonary artery index was calculated according to Nakata: pulmonary artery index = right pulmonary artery area $\left(\mathrm{mm}^{2}\right)+$ left pulmonary artery area $\left(\mathrm{mm}^{2}\right)$ /body surface area $\left(\mathrm{m}^{2}\right) .{ }^{12}$ The pulmonary artery index was expressed as the difference between the expected normal value and the measured value for each patient.

\section{MOLECULAR STUDIES}

EDTA blood samples were collected from the affected individuals $(2-3 \mathrm{ml})$ and their parents $(10 \mathrm{ml})$.

Microsatellite polymorphic DNA markers (D22S264, D22S941, and D22S944) mapping within the commonly deleted region of CATCH22 were used for identification of chromosome 22q11 microdeletion in 42 patients. ${ }^{13}$ Polymerase chain reaction (PCR) genotyping was performed as previously described. ${ }^{14}$ The location of the three polymorphic CA repeats is as follows: cen-TUPLE1D22S941-D22S944-COMT-D22S264ZNF74. ${ }^{15}$ The sensitivity of this method is $>95 \%$.

In the remaining 52 patients, the fluorescent in situ hybridisation (FISH) study technique was used to diagnose the $22 \mathrm{q} 11$ microdeletion (probe Sc11.1 D22S139). ${ }^{16}$ When another chromosomal anomaly or syndrome was suspected, a standard or high resolution karyotype analysis was performed.

\section{STATISTICS}

Data are expressed as mean (SD) for continuous variables, as median and quartiles for ordinal variables, and as frequency for nominal variables. The normality of the distributions was controlled as appropriate by the WilkShapiro test. Frequencies of each associated cardiovascular anomaly associated with deleted chromosome 22 and those associated without this deletion were analysed with the $\chi^{2}$ statistic and the Fisher exact probability test. For each patient the size of the pulmonary arteries was expressed in SD compared with the normal mean \pm 1 SD. Differences in the size of the pul-

Table 1 Pulmonary artery (PA) anomalies in del22q and non-del22q patients

\begin{tabular}{lcl}
\hline Anomaly & 22q11 deletion $(n=25)$ & No 22q11 deletion $(n=69)$ \\
\hline $\begin{array}{l}\text { Absent confluent central PA } \\
\begin{array}{l}\text { Absent pulmonary trunk (in patients } \\
\text { without MAPCA) }\end{array}\end{array}$ & $3 / 25(12 \%)$ & $3 / 69(4 \%)$ \\
MAPCA & $1 / 15(6 \%)$ & $9 / 66(13.5 \%)$ \\
\hline
\end{tabular}

${ }^{\star} \mathrm{p}<0.001$.

MAPCA, major aortopulmonary collateral arteries.

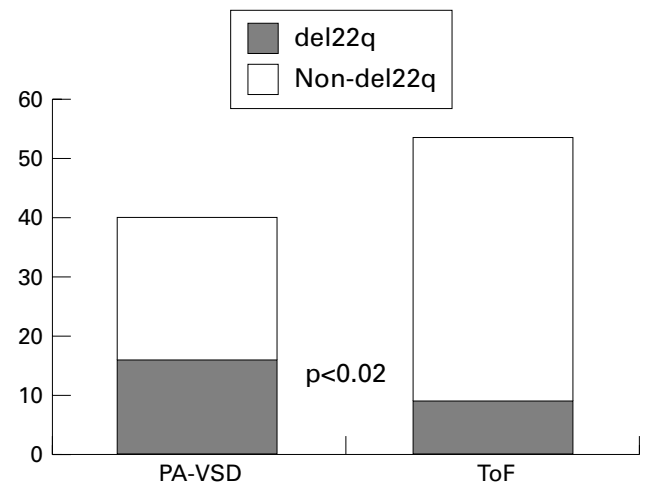

Figure 1 Distribution of tetralogy of Fallot $\left(T_{o} F\right)$ and pulmonary atresia-ventricular septal defect (PA-VSD) in the group del $22 q$ and in the group non-del22q.

monary arteries between the different groups were then tested with the Mann-Whitney U test. All the tests were two sided. A p value $<0.05$ was considered significant.

\section{Results}

OVERALL DATA

Fifty four patients had tetralogy of Fallot and 40 PA-VSD. Twenty five patients had $22 \mathrm{q} 11$ deletion (del22q; 26.5\%). In the remaining 69 patients (non-del22q), eight other chromosomal anomalies were identified: Down syndrome $(n=3)$, trisomy $18 \mathrm{r}(\mathrm{n}=1)$, trisomy 8 with mosaicism $(n=1)$, interstitial inversion of chromosome 12 ( $n=1)$, translocation 4-20 ( $n$ $=1$ ), and Pallister-Killian syndrome $(n=1)$. In addition, three other syndromes were identified in this group: Pierre Robin sequence $(n=1)$, branchio-oro-facial syndrome $(\mathrm{n}=1)$, and CHARGE association $(n=1)$. Overall, $38.3 \%$ of the patients enrolled in our study had either a karyotypic anomaly, a 22q11 deletion, or a well recognised genetic syndrome.

\section{CARDIOVASCULAR ANOMALIES}

The distribution of tetralogy of Fallot and PA-VSD in the group del22q and in the group non-del22q was significantly different $(16 / 40$ PA-VSD del22q and 9/54 tetralogy of Fallot del22q; $\chi^{2}=6.5, p<0.02$; fig 1 ). Anomalies of the arterial duct were more frequent in the del22q group: absent arterial duct $(36 \% v 4 \%$, $\mathrm{p}=0.0003)$, abnormal origin of the arterial duct with tortuous course $(32 \%$ v $9 \%$, $\mathrm{p}=0.009)$. Anomalies of the aortic arch were not different in the two groups (32\% v 36\%). Similarly, an aberrant subclavian artery was observed in the same proportion in the two groups $(12 \% v 10 \%)$. No coronary artery distribution anomaly was observed in this series.

\section{PULMONARY VESSELS}

The prevalence of anomalies of the pulmonary trunk and central pulmonary arteries and of major aortopulmonary collateral arteries in the del22q and non-del22q patients is summarised in table 1 . The morphology and distribution of the collaterals were different in del22q and non-del22q patients (figs 2 and 3 ). In the three non-del22q patients, we observed one direct (type II) major aortopulmonary collateral artery in the first patient, one type II and one 


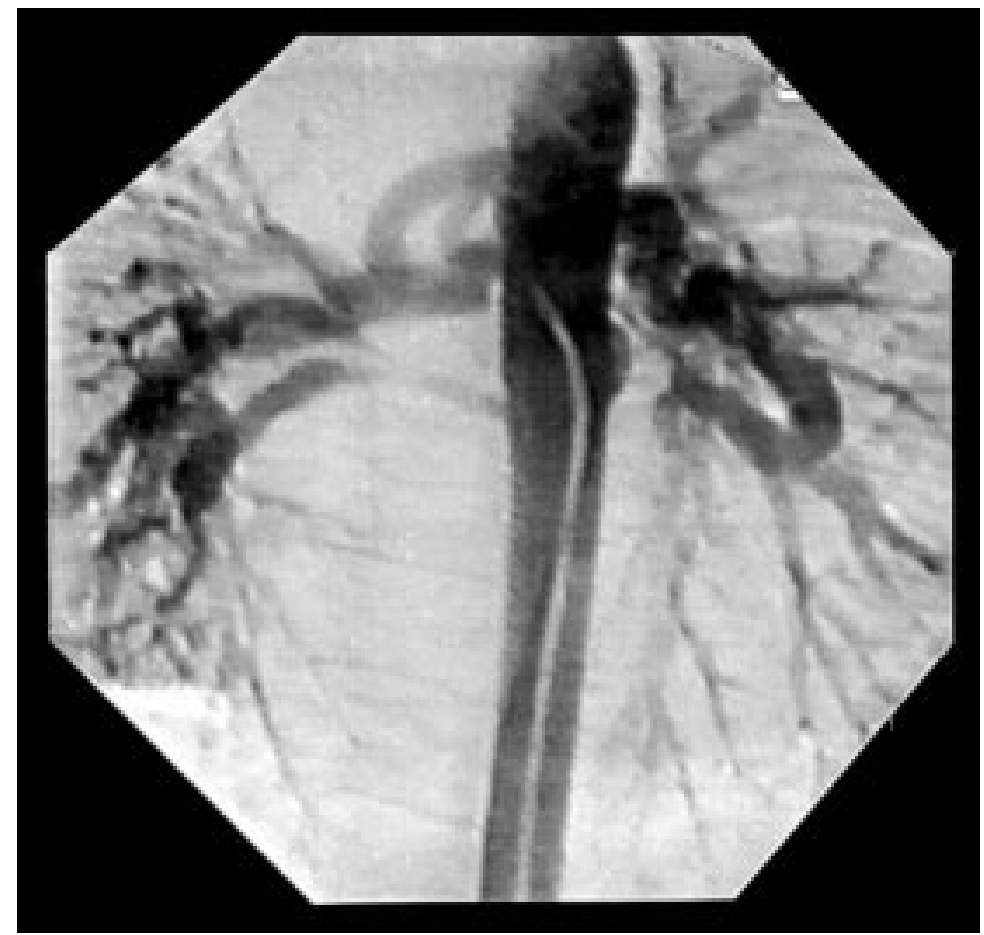

Figure 2 Major aortopulmonary collateral arteries with complex loop morphology in a patient with pulmonary atresia-ventricular septal defect and del22q. type III in the second patient, and two type III in the third. The two type II major aortopulmonary collateral arteries did not connect to the central pulmonary arteries in this group. In the 10 del22q patients, at least three major aortopulmonary collateral arteries were identified in each patient. The majority of these originated from the descending aorta. They had a complex loop course and represented the main source of blood for the lung in all (fig 3). At least one of these collaterals connected to the central pulmonary arteries in eight patients.

The size of the right and left pulmonary arteries was expressed as a standard deviation (SD) difference from the normal range for body surface area. The size of the right and left pulmonary arteries was -4.2 (quartiles; $95 \%$ confidence interval $(\mathrm{CI})-5.3$ to -2.9$)$ for PA-VSD del22q and $-2.6(95 \% \mathrm{CI}-3.1$ to $-1.8)$ for PA-VSD non-del22q $(p=0.02)$. In addition, the difference between measured and theoretical Nakata index was -373 (94) in PA-VSD del22q $v-245$ (93) in PA-VSD nondel22q $(p=0.0002)$. If we excluded the patients with major aortopulmonary collateral arteries, we did not find a significant difference in the Nakata index between PA-VSD del22q and PA-VSD non-del22q (-338 (111) $v-249$ $(78) ; p=0.05)$. In tetralogy of Fallot with and without del22q, the size of the pulmonary arteries was equivalent $(-208$ (167) $v-181$ $(136) ; \mathrm{p}=0.6)$

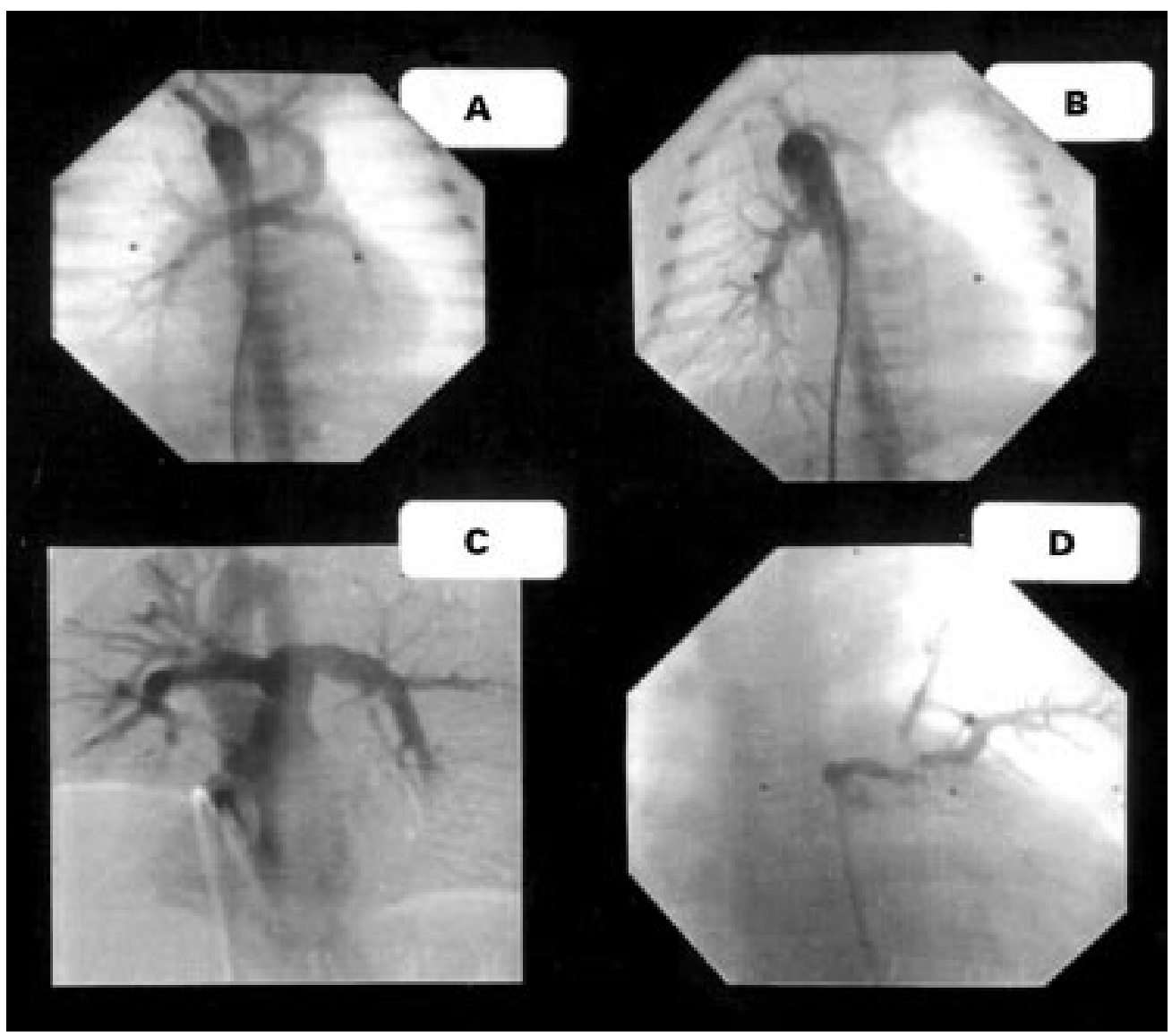

Figure 3 Variability of the phenotype of the pulmonary vessels in non-del22q patients. (A) Pulmonary atresia-ventricula septal defect (PA-VSD) with right aortic arch and a ductus arteriosus originating from the left common brachiocephalic artery; (B) right aortic arch with indirect major aortopulmonary collateral arteries (MAPCA) in a patient with PA-VSD; (C) tetralogy of Fallot with left aortic arch; (D) selective injection in a direct MAPCA. 


\section{Discussion}

The association of conotruncal cardiac defects with hemizygosity of a locus on chromosome 22 is one of the most dramatic and clinically important pieces of recent evidence for genetic aetiologies of congenital heart defects. ${ }^{17}{ }^{18}$ As molecular probes for this locus are readily available, the diagnosis of a chromosome $22 \mathrm{q}$ microdeletion is now routinely performed in neonates-as well as in fetuses-with conotruncal heart defects. ${ }^{1416}$ Microdeletion syndromes are more amenable to molecular analysis than other chromosomal anomalies. ${ }^{19}$ Hitherto, however, it remains unknown why this haploinsufficiency shows such a wide range of penetrance and expressivity. Several hypotheses have been formulated to explain the wide spectrum of congenital heart defects encountered in del22q patients. ${ }^{19}$ Mapping studies suggest that the size of the deletion does not correlate with the phenotype and it is still unclear whether the DiGeorge syndrome is a contiguous gene syndrome or is due to the alterations in a single gene. ${ }^{15} 20$

\section{GENOTYPE-PHENOTYPE CORRELATION}

Genotype-phenotype correlations may provide an improved understanding of the molecular basis of these congenital heart diseases. In fact, genetic heterogeneity of conotruncal heart anomalies has not been clearly demonstrated. Similar anomalies are described in infants with and without del22q, but on the basis of our study it appears that these malformations are not totally identical. ${ }^{9}{ }^{10}$ In addition, the ratio of patients del $22 \mathrm{q} /$ non-del $22 \mathrm{q}$ in each of these conotruncal defects implies that some of these latter are almost specific for del22q. ${ }^{21}$ These results suggest that different embryological mechanisms are responsible for a similar defect when associated or not with del22q. Recently, phenotypic differences in patients with PAVSD and tetralogy of Fallot with and without del22q have been described. ${ }^{9} 1022$ The additional relevant anomalies in del22q patients in these previously reported series were to some extent different from our observations. In fact, anomalies of the aortic arch and of the subclavian artery origin were not different in del22q patients in our series. Our findings in the pulmonary vasculature differ from those previously described by Momma et al. ${ }^{9}{ }^{10}$ Absent confluent central pulmonary arteries and pulmonary trunk was frequent in del22q patients in this latter series. ${ }^{10}$ Conversely, these findings were rare in our study. Notwithstanding this dissimilarity between the two series, the size of the central pulmonary arteries in PA-VSD-del22q was very small in our series. In Momma's series, ${ }^{910}$ there is a bias of recruitment as the investigators' institution is a referral centre for the treatment of complex tetralogy of Fallot. Further, the selection of the control patients is not described. In our study, we included prospectively both del22q and non-del22q patients, to do away with bias in recruitment. The 10 patients with either a chromosomal anomaly or a well recognised syndrome were analysed with the non-del22q patients, though this may raise the issue of het- erogeneity in the non-del22q group. In addition, the precise anatomy of the pulmonary vasculature was available in all. Finally, our observations regarding the size of the pulmonary arteries and the major aortopulmonary collaterals in newborns and young infants (less than six months of age) suggest that these anomalies were present before birth and were not acquired.

DEVELOPMENT OF THE PULMONARY VESSELS Regarding major aortopulmonary collaterals, and from a clinical point of view, it is of interest to know whether we are dealing with the persistence of transient embryological vessels or with the prenatal and postnatal recruitment of the bronchial vasculature that normally supplies the lung. The place of origin, course, and branching pattern of the major aortopulmonary collaterals, as well as the size of the pulmonary arteries, may vary because of the exact timing and degree of maldevelopment that occurs in the pulmonary outflow tract. ${ }^{23}$ According to DeRuiter et $a l,{ }^{24}$ the splanchnic vascular plexus communicates by luminal connections developing with the aorta and the intercostal arteries during two periods separated by an interposed period. The pattern of the early aortopulmonary connections may correspond to the major aortopulmonary collaterals with complex loop morphology in del22q patients. As the morphology of the major collaterals in non-del22q patients is different, with a high frequency of the indirect type, we can hypothesise that they are the remnants of the second set of aortopulmonary connections. We are aware that the common origin of these two groups of major aortopulmonary collaterals makes differentiation difficult.

Together with the potential difference in the timing of the process that gives rise to conotruncal heart defects in del22q and non-del22q, a disparity in premigratory neural crest region involvement may result in the observed phenotypic differences. ${ }^{25}{ }^{26}$ Basic differences in the ectomesenchyme in various regions of the pharyngeal arches have been described. ${ }^{27}$ The genes responsible for tetralogy of Fallot and PA-VSD in del22q and nondel22q patients may have different effects on the development of neural crest derived populations.

\section{CONCLUSION}

Our study confirms that morphological features of tetralogy of Fallot and PA-VSD appear to be grossly different in patients with and without $22 q$ deletion. We were able to describe a "specific" phenotype of PA-VSD-del22q characterised by major aortopulmonary collaterals with complex loop morphology originating from the descending aorta. In tetralogy of Fallot and in PA-VSD without major aortopulmonary collaterals, phenotypic variations between del22q and non-del22q patients are subtle and do not lead to easy differentiation between these groups of patients with respect to the cardiac phenotype. Histological studies of the collateral and central pulmonary arteries 
might be used as a possible differentiating factor. In addition, specific approaches for angiographic evaluation of these patients could be defined and, hopefully, provide clues for a surgical strategy.

1 Burn J, Takao A, Wilson D, et al. Conotruncal anomaly face syndrome associated with a deletion within chromosome 22q11. F Med Genet 1993;30:822-4.

2 Driscoll DA, Spinner NB, Budarf ML, et al. Deletions and microdeletions $22 \mathrm{q} 11.2$ in velocardiofacial syndrome. $A m$ f Med Genet 1992;44:261-8.

3 Gianotti A, Digilio MC, Marino B, et al. Cayler cardiofacial Gianotti A, Digilio MC, Marino B, et al. Cayler cardiofacial syndrome and del 22q11: part of the
phenotype. Am $\mathcal{F}$ Med Genet 1994;53:285-6.

4 Scambler PJ, Carey AH, Wyse RKH, et al. Microdeletion within 22q11 associated with sporadic and familia DiGeorge syndrome. Genomics 1991;10:201-6.

5 Moerman P, Goddeenis P, Lauwerijns J, et al. Cardiovascular malformations in DiGeorge syndrome. Br Heart $\mathcal{F}$ 1980;44:452-9.

6 LeLièvre CS, LeDouarin NM. Mesenchymal derivatives of the neural crest: analysis of chimeric quail and chick embryos. F Anat 1975;139:491-512.

7 Kirby ML, Gale TF, Stewart DE. Neural crest cells contribute to aorticopulmonary septation. Science 1983;220:105961.

8 Wilson DI, Burn J, Scambler P, et al. DiGeorge syndrome: part of CATCH22. ₹ Med Genet 1993;30:852-6.

9 Momma K, Kondo C, Matsuoka R. Tetralogy of Fallot with pulmonary atresia associated with chromosome 22q11 pulmonary atresia associated with chromoson

10 Momma K, Kondo C, Ando M, et al. Tetralogy of Fallot associated with chromosome $22 \mathrm{q} 11$ deletion. Am 7 Cardiol 1995;76:618-21.

11 Rabinovitch M, Herrera-deLeon V, Castaneda A, et al. Growth and development of the pulmonary vascular bed in patients with tetralogy of Fallot with or without pulmonary atresia. Circulation 1981;64:1234-49.

12 Nakata S, Imai Y, Takanashi Y, et al. A new method for the quantitative standardization of cross-sectional areas of the pulmonary arteries in congenital heart diseases with decreased pulmonary blood flow. 7 Thorac Cardiovasc Surg 1984;88:610-19.
13 Marineau C, Aubry M, Julien JP, et al. Dinucleotide repeat polymorphism at the D22S264 locus. Nucleic Acids Res polymorphism

14 Bonnet D, Cormier V, Kachaner J, et al. Microsatellite DNA markers detect $95 \%$ of chromosome 22q11 deletions. $A m \mathcal{F}$ Med Genet 1997;68:182-4.

15 Morrow B, Goldberg R, Carlson C, et al. Molecular definition of the 22q11 deletions in velo-cardio-facial syndrome. Am f Hum Genet 1995;56:1391-403.

16 Desmaze C, Scambler PJ, Prieur M, et al. Routine diagnosis of DiGeorge syndrome by fluorescent in situ hybridization. Hum Genet 1993;90:663-5.

17 Payne RM, Johnson MC, Grant JW, et al. Toward a molecular understanding of congenital heart disease. Circulation 1995;91:494-504.

18 Lewin MB, Lindsay EA, Baldini A. 22q11 deletions and cardiac disease. Prog Pediatr Cardiol 1996;6:19-28.

19 Fisher E, Scambler P. Human haploinsufficiency-one for sorrow, two for joy. Nature Genet 1994;7:5-7.

20 Budarf ML, Collins J, Gong W, et al. Cloning a balanced translocation associated with DiGeorge syndrome and identification of a disrupted candidate gene. Nature Genet 1995 1995;10:269-78.

21 Lewin M, Lindsay E, Jurecic V, et al. A genetic etiology for interrupted aortic arch type B [abstract]. Circulation 1996; 94:I-55.

22 Marino B, Digilio MC, Grazioli S, et al. Associated cardiac anomalies in isolated and syndromic patients with tetralogy of Fallot. Am f Cardiol 1996;77:505-8.

23 DeRuiter MC, Gittenberg-de Groot AC, Poelmann RE, et al. Development of the pharyngeal arch system related to the pulmonary and bronchial vessels in the avian embryo with a concept on systemic-pulmonary collateral formation. Circulation 1993;87:1306-19.

24 DeRuiter MC, Gittenberg-de Groot AC, Bogers AJJC, et al. The restricted surgical relevance of morphologic criteria to classify systemic-pulmonary collateral arteries in pulmonary atresia with ventricular septal defect. $\mathcal{F}$ Thorac Cardiovasc Surg 1994;108:692-9.

25 Kirby MI Cardiac morphogenesis: recent research adKirby ML. Cardiac morphogenesis:
vances. Pediatr Res 1987;21:219-24.

26 Nishibatake M, Kirby ML, Van Mierop LHS. Pathogenesis of persistent truncus arteriosus and dextroposed aorta in the chick embryo after neural crest ablation. Circulation 1987;75:255-64.

27 Nakamura H. Mesenchymal derivatives of the neural crest. Arch Histol fpn 1982;45:127-38. 